\title{
Structure of the exopolysaccharide produced by Streptococcus thermophilus S3
}

\author{
Elisabeth J. Faber, Mischa J. van den Haak, Johannis P. Kamerling,* \\ Johannes F.G. Vliegenthart \\ Department of Bio-Organic Chemistry, Bijvoet Center, Utrecht University, PO Box 80.075, \\ NL-3508 TB Utrecht, The Netherlands
}

Received 16 October 2000; accepted 9 January 2001

\begin{abstract} show the polysaccharide to have the following structure:

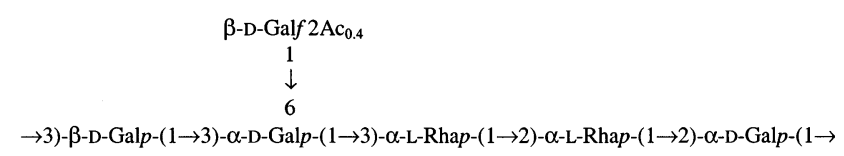

(C) 2001 Elsevier Science Ltd. All rights reserved.
\end{abstract}

The exopolysaccharide of Streptococcus thermophilus S3, produced in skimmed milk, is composed of D-galactose and L-rhamnose in a molar ratio of 2:1. The polysaccharide contains 0.4 equiv of $O$-acetyl groups per repeating unit. Linkage analysis and 1D/2D NMR $\left({ }^{1} \mathrm{H}\right.$ and $\left.{ }^{13} \mathrm{C}\right)$ studies on native and O-deacetylated EPS together with nanoES-CID tandem mass spectrometry studies on oligosaccharides generated by a periodate oxidation protocol,

Keywords: Lactic acid bacteria; Exopolysaccharide; Streptococcus thermophilus; Structural analysis

\section{Introduction}

In the food industry, microbial exopolysaccharides (EPSs) are widely applied as thickening, gelling and stabilizing agents. ${ }^{1}$ Lactic acid bacteria, which carry the GRAS (generally recognized as safe) status, are excellent sources of such food grade exopolysaccharides. For example, when applied in food fermentation, the in situ production of exopolysaccharides will contribute to the texture of the product.

* Corresponding author. Tel.: + 31-30-2533479; fax: + 3130-2540980.

E-mail address: kame@boc.chem.uu.nl (J.P. Kamerling).
In order to initiate studies that may provide a better insight into the relationship between the structure of polysaccharides from lactic acid bacteria and the consistency of fermented products, detailed structural investigations have been performed on exopolysaccharides produced by different bacterial strains including Lactobacillus acidophilus, ${ }^{2}$ Lactobacillus delbrueckii subsp. bulgaricus $\mathrm{rr}^{3}{ }^{3}$ Lactobacillus helveticus, ${ }^{4-8}$ Lactobacillus paracasei,${ }^{9}$ Lactobacillus reuteri, ${ }^{10}$ Lactobacillus rhamnosus, ${ }^{11}$ Lactobacillus sake, ${ }^{12}$ Lactococcus lactis subsp. cremoris, ${ }^{13,14}$ and Streptococcus thermophilus. ${ }^{15-18}$

S. thermophilus strains in combination with Lb. delbrueckii subsp. bulgaricus strains are used as commercial yogurt starters. The structure of their exopolysaccharides, as well as the 
rheological properties of their subsequent yogurt gels, are studied in order to unravel the mechanisms by which the cultures and their exopolysaccharides influence the consistency of the yogurt. ${ }^{18}$

Here, we report the structural determination of the exopolysaccharide produced by the highly ropy $S$. thermophilus S3 strain in skimmed milk.

\section{Results and discussion}

Isolation, purification, and composition of the polysaccharides. - The exopolysaccharide, produced by $S$. thermophilus $\mathrm{S} 3$ in pasteurized reconstituted skimmed milk, was isolated, and purified via ethanol precipitation followed by acetone precipitation. The purity of the polysaccharide was confirmed by ${ }^{1} \mathrm{H}$ NMR spectroscopy (vide infra). From the $S$. thermophilus S3 culture, $36 \mathrm{mg} / \mathrm{L}$ of polysaccharide with an average molecular mass of $5.9 \times 10^{3} \mathrm{kDa}$ was isolated.

Monosaccharide analysis of the native polysaccharide (n-EPS), including the determination of absolute configurations, revealed the presence of $\mathrm{D}-\mathrm{Gal}$ and $\mathrm{L}-\mathrm{R}$ ha in a molar ratio of 2:1. Methylation analysis of n-EPS (Table 1) demonstrated the presence of 2- and 3-substituted Rhap, 2-, 3-, and 3,6-substituted Galp and terminal Galf in equal molar amounts,

Table 1

Methylation analysis data of $S$. thermophilus S3 native EPS (n-EPS), O-deacetylated EPS (dAc-EPS), and n-EPS after mild acid hydrolysis (hyd-EPS)

\begin{tabular}{|c|c|c|c|}
\hline \multirow[t]{2}{*}{ Derivative } & \multicolumn{3}{|c|}{ Molar amounts ${ }^{a}$} \\
\hline & n-EPS & dAc-EPS & hyd-EPS \\
\hline $2,3,5,6-\mathrm{Gal}^{\mathrm{b}}$ & 0.9 & 0.9 & 0.4 \\
\hline $2,3,4,6-\mathrm{Gal}$ & & & 0.7 \\
\hline $3,4,6-\mathrm{Gal}$ & 1.0 & 1.0 & 1.0 \\
\hline $2,4,6-\mathrm{Gal}$ & 1.0 & 1.0 & 1.7 \\
\hline 2,4-Gal & 1.0 & 1.0 & 0.3 \\
\hline 3,4-Rha & 1.0 & 1.0 & 1.0 \\
\hline 2,4-Rha & 1.0 & 1.1 & 0.9 \\
\hline
\end{tabular}

a $3,4,6-\mathrm{Gal}$ is taken as 1.0 .

b $2,3,5,6-\mathrm{Gal}=1,4$-di- $O$-acetyl-2,3,5,6-tetra- $O$-methyl-galactitol-1- $d$, etc. indicating a branched hexasaccharide repeating unit. To determine the position of the acid-labile terminal Gal $f$ residue, n-EPS was treated with $0.3 \mathrm{M}$ trifluoroacetic acid (20 min, $100^{\circ} \mathrm{C}$ ), then subjected to methylation analysis (hyp-EPS). A 70\% conversion of 3,6substituted Gal $p$ into 3-substituted Gal $p$, together with a decrease in the amount of terminal Galf (Table 1), demonstrated that in the native polysaccharide, the terminal Gal $f$ residue is attached to O-6 of the 3,6-substituted Gal $p$ residue. The terminal Gal $p$ derivative observed in the methylation analysis of the hydrolyzed sample originates from hydrolytically released Galf.

Treatment of n-EPS with $5 \%(\mathrm{w} / \mathrm{v}) \mathrm{NH}_{4} \mathrm{OH}$ at room temperature resulted in complete $\mathrm{O}$ deacetylation of the polysaccharide (dAcEPS), as determined by ${ }^{1} \mathrm{H} \quad$ NMR spectroscopy (vide infra). Monosaccharide and methylation analysis (Table 1) indicated no additional changes of the O-deacetylated polysaccharide.

The 1D ${ }^{1} \mathrm{H}$ NMR spectrum of n-EPS (Fig. 1(A)) shows a complex signal pattern in terms of peak intensities in the anomeric region $(\delta$ 5.4-4.5) due to partial O-acetylation $(O$-acetyl, $\delta$ 2.148). After O-deacetylation of the polysaccharide (dAc-EPS), the pattern changes into five anomeric signals (Fig. 1(B)), of which the signal at $\delta \sim 5.16$ represents two anomeric protons, indicating a hexasaccharide repeating unit. A distinction between the anomeric signal of residue $\mathbf{D}(\delta$ 5.16) and residue $\mathbf{E}(\delta$ 5.17) could be made in the TOCSY spectra (vide infra). Furthermore, high-field signals $(\delta \sim 1.3)$ are present, arising from the methyl groups of Rhap residues. The partial O-acetylation in n-EPS is reflected in the 1D ${ }^{1} \mathrm{H}$ NMR spectrum of n-EPS by an additional signal in the anomeric region at $\delta$ 4.958 for the proton at the O-acetylated carbon and a broadening of the anomeric signal at $\delta \sim 5.16$ originating from a contribution of $\mathrm{H}-1$ of the O-acetylated residue. Based on integration of the anomeric signals in the spectrum, the extent of $\mathrm{O}$-acetylation was determined to be 0.4 equiv. However, it must be kept in mind that the procedure used for the isolation of the polysaccharide may have resulted in partial O-deacetylation. The resolu- 


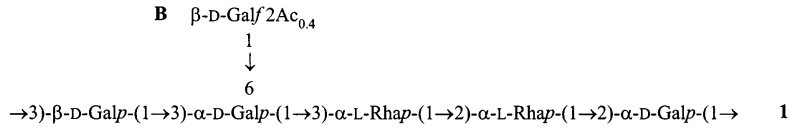

A

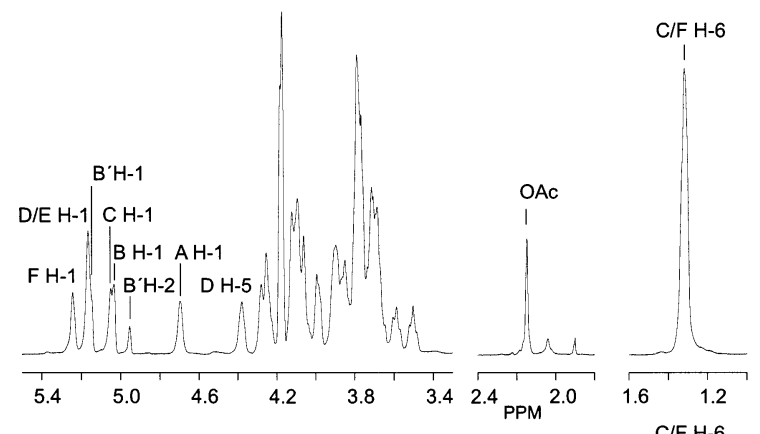

B

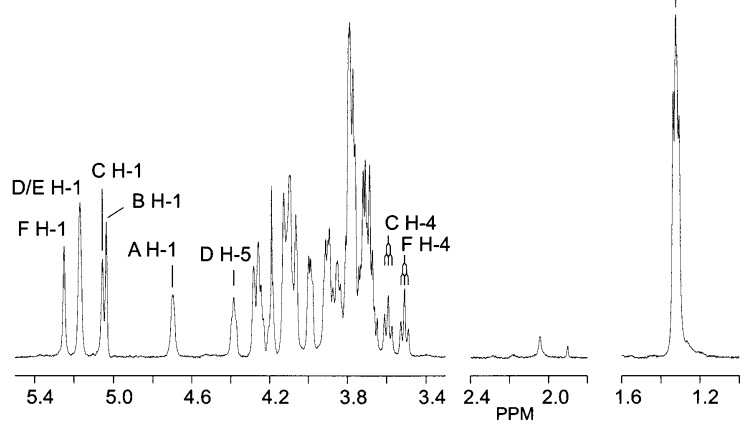

Fig. 1. $500-\mathrm{MHz}{ }^{1} \mathrm{H}$ NMR spectra of n-EPS 1 (A), and dAc-EPS 2 (B) produced by $S$. thermophilus $\mathrm{S} 3$, recorded in $\mathrm{D}_{2} \mathrm{O}$ at $80^{\circ} \mathrm{C}$.

tion of the dAc-EPS spectrum (Fig. 1(B)) is higher than the resolution of the n-EPS spectrum (Fig. 1(A)).

For the assignment of the acetylated hexasaccharide repeating unit, the constituting residues are labeled $\mathbf{A}-\mathbf{F}$ according to the increasing chemical shift values of the anomeric protons.

By making use of the 1D ${ }^{1} \mathrm{H}$ NMR spectrum, the $2 \mathrm{D}^{13} \mathrm{C}-{ }^{1} \mathrm{H}$ HSQC spectrum of dAcEPS (vide infra) allowed the assignment of the chemical shifts of the corresponding anomeric carbon signals. The spectrum contains of six anomeric signals at $\delta 96.0$ (residue $\mathbf{E},{ }^{1} J_{\mathrm{C}-1, \mathrm{H}-1}$ $176 \mathrm{~Hz}$ ), $\delta 97.0$ (residue $\mathbf{D},{ }^{1} J_{\mathrm{C}-1, \mathrm{H}-1} 171 \mathrm{~Hz}$ ),$\delta$ 100.9 (residue $\mathbf{F},{ }^{1} J_{\mathrm{C}-1, \mathrm{H}-1} 177 \mathrm{~Hz}$ ), $\delta 102.4$ (residue $\mathbf{C},{ }^{1} J_{\mathrm{C}-1, \mathrm{H}-1} 174 \mathrm{~Hz}$ ), $\delta 104.8$ (residue A, ${ }^{1} J_{\mathrm{C}-1, \mathrm{H}-1} 163 \mathrm{~Hz}$ ), and $\delta 108.1$ (residue B, ${ }^{1} J_{\mathrm{C}-1, \mathrm{H}-1} 177 \mathrm{~Hz}$ ), respectively, confirming the proposed hexasaccharide repeating unit. Based on the observed ${ }^{1} J_{\mathrm{C}-1, \mathrm{H}-1}$ values, it could be deduced that residue $\mathbf{A}$ has the $\beta$ anomeric configuration, whereas residues $\mathbf{C}, \mathbf{D}, \mathbf{E}$ and $\mathbf{F}$ have the $\alpha$ anomeric configurations. The relatively large ${ }^{1} J_{\mathrm{C}-1, \mathrm{H}-1}$ values of residues $\mathbf{E}$ and $\mathbf{F}$ have been reported before for 2-substituted monosaccharides. ${ }^{18}$ Since residue $\mathbf{B}$ is a Gal $f$ residue (vide infra), ${ }^{1} J_{\mathrm{C}-1, \mathrm{H}-1}$ will give no information about the anomeric configuration of the residue.

Periodate oxidation. - The methylated material, obtained after periodate oxidation of n-EPS and subsequent reduction $\left(\mathrm{NaBH}_{4}\right)$, methylation $\left(\mathrm{CH}_{3} \mathrm{I}\right)$, mild acid hydrolysis, reduction $\left(\mathrm{NaBD}_{4}\right)$, and methylation $\left(\mathrm{CD}_{3} \mathrm{I}\right)$, was dissolved in a water-methanol mixture and analyzed by nanoES-CID tandem mass spectrometry. In the high-mass region of the ES mass spectrum, an $[\mathrm{M}+\mathrm{Na}]^{+}$ion at $m / z$ 837 was detected, corresponding to an O-permethylated alditol $\left(\mathrm{Hex}_{2} \mathrm{Pen}_{1}\right.$ Deoxyhex $\left._{1}\right)-1-d$ containing three deuterated methyl groups. The tandem mass spectrum obtained on collision activation of $m / z 837$ (Fig. 2) contains sodium-cationized $\mathbf{Y}_{\mathbf{n}}$ fragments at $m / z 252$,
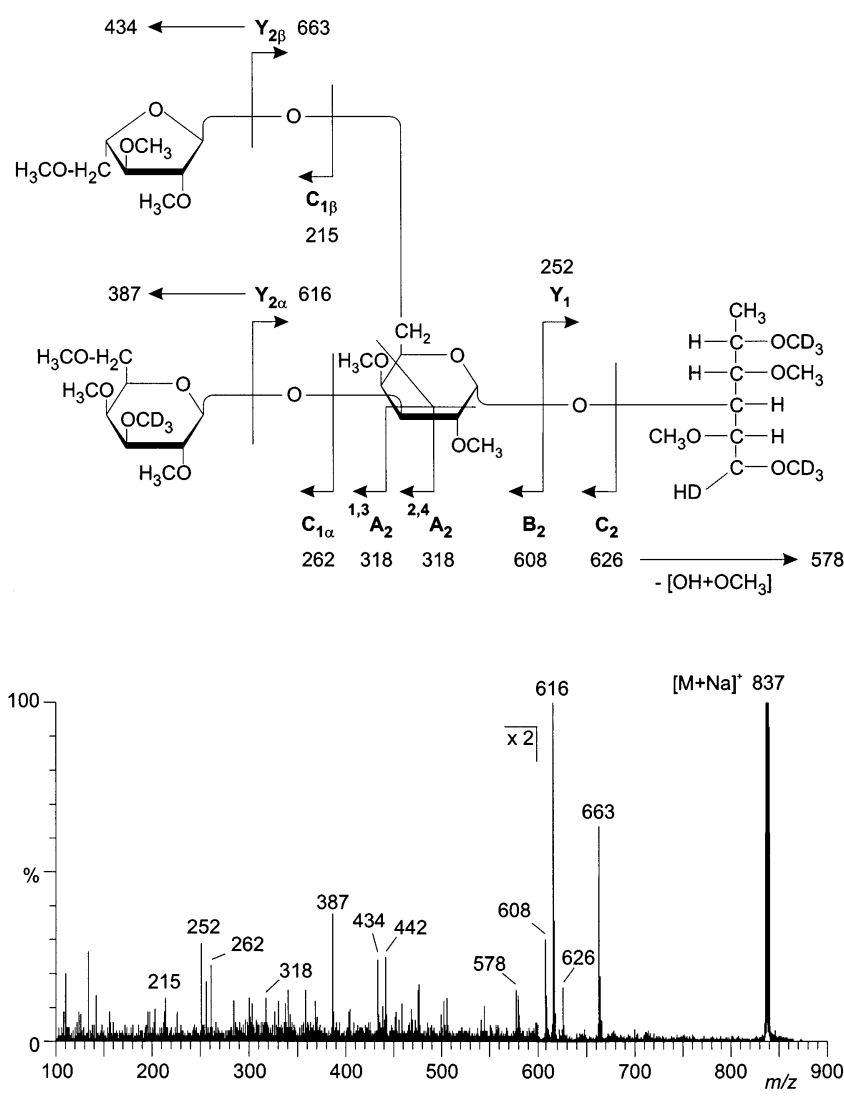

Fig. 2. Positive-ion mode nanoES-CID tandem mass spectrum of sodiated ions of the tetrasaccharide product obtained by a periodate oxidation protocol. 
616, and 663 and sodium-cationized $\mathbf{C}_{\mathbf{n}}$ fragments at $m / z 215,262$, and 626. The $\mathbf{Y}_{1}$ ion at $\mathrm{m} / \mathrm{z} 252$ suggests the presence of a deoxyhexitol-1-d containing two deuterated methyl groups at the reducing end of the oligosaccharide. The signals at $m / z 616$ and 663, corresponding to the $\mathbf{Y}_{2 \alpha}$ and $\mathbf{Y}_{2 \beta}$ ions, respectively, are indicative of a disubstituted hexose linked to the deoxyhexitol-1- $d$, and thus reflect a branched structure. The $\mathbf{C}_{1 \alpha}$ ion at $m / z 262$ corresponds to a terminal hexose containing one deuterated methyl group and the $\mathbf{C}_{\mathbf{1}}$ ion at $m / z 215$ corresponds to a terminal pentose. In view of the monosaccharide and methylation analysis data (vide supra), the pentose has to originate from the Gal $f$ residue since selective degradation of the side chain of Galf by periodate oxidation followed by reduction results in the formation of Araf. ${ }^{19}$ Secondary fragment ions are observed at $m / z$ 387, 434, and 442. The ion at $m / z 387$ results from the loss of (deutero)methylated deoxyhexitol-1- $d$ from the $\mathbf{Y}_{2 \alpha}$ ion $(m / z 616-229)$, while the ion at $m / z \quad 434$ results from the loss of (deutero)methylated deoxyhexitol-1- $d$ from the $\mathbf{Y}_{2 \beta}$ ion $(m / z 663-229)$. The ion at $m / z 442$ is the result of the loss of a terminal methylated pentose and a terminal (deutero)methylated hexose from the pseudo-molecular ion $(m / z$ 837-174-221). Furthermore, the ion at $m / z 578$ results from the loss of a hydroxy group at $\mathrm{C}-1$ and an $O$-methyl group at $\mathrm{C}-2$ forming a double bond between $\mathrm{C}-1$ and $\mathrm{C}-2$ at the reducing end of the $\mathbf{C}_{2}$ ion $\left(\mathbf{C}_{2}-[\mathrm{OH}+\right.$ $\left.\left.\mathrm{OCH}_{3}\right]\right) .{ }^{20}$

In addition to ions resulting from the cleavage of glycosidic linkages $\left(\mathbf{C}_{\mathbf{n}}\right.$ and $\left.\mathbf{Y}_{\mathbf{n}}\right),{ }^{\mathbf{1} 3} \mathbf{A}_{\mathbf{2}}$ and ${ }^{\mathbf{2 , 4}} \mathbf{A}_{\mathbf{2}}$ ions resulting from cross-ring cleavage, are observed at $m / z 318$. The number of ions obtained from cross-linkage cleavages in this spectrum is insufficient to assign linkage types. However, combining methylation analysis data (vide supra) and the knowledge that periodate oxidation causes cleavage of 1,2-diol groups in 2-linked residues, provides proof for the selective removal of the 2-linked residues, leaving three 3-linked residues and a 6-linked terminal Galf.

The results obtained from the ES-MS/MS spectrum together with those from the monosaccharide and methylation analyses performed on n-EPS, allowed the partial structure to be formulated as:

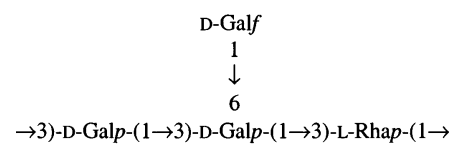

In view of the final structure (vide infra), one would expect the isolated tetrasaccharide to contain an additional glycerol group at the reducing end. The absence of this group is due to the hydrolysis of the labile rhamnosyl glyceraldehyde linkage in the reduced and O-permethylated periodate-oxidized material.

In addition to the $[\mathrm{M}+\mathrm{Na}]^{+}$ion at $m / z$ 837 originating from the tetrasaccharide-alditol as illustrated above, the ES mass spectrum revealed amongst others, $[\mathrm{M}+\mathrm{Na}]^{+}$ions at $m / z$ 503, 506, 677, and 680. The tandem mass spectrum obtained from the $[\mathrm{M}+\mathrm{Na}]^{+}$ion at $m / z 677$ contains sodium-cationized $\mathbf{Y}_{\mathbf{n}}$ fragments at $\mathrm{m} / \mathrm{z} 252$ and 456 and sodium-cationized $\mathbf{C}_{\mathbf{n}}$ fragments at $m / z 262$ and 466, indicating an O-permethylated alditol $\left(\mathrm{Hex}_{2}\right.$ Deoxyhex $\left._{1}\right)-1-d$ containing three deuterated methyl groups. Furthermore, the tandem mass spectrum obtained from the $[\mathrm{M}+\mathrm{Na}]^{+}$ ion at $\mathrm{m} / \mathrm{z} 680$ reveals sodium-cationized $\mathbf{Y}_{\mathbf{n}}$ fragments at $\mathrm{m} / \mathrm{z} 252$ and 459 and sodiumcationized $\mathbf{C}_{\mathbf{n}}$ fragments at $m / z 262$ and 469, indicating a O-permethylated alditol $\left(\operatorname{Hex}_{2}\right.$ Deoxyhex $\left._{1}\right)-1-d$ containing four deuterated methyl groups. Taking into account the tetrameric product generated by the periodate oxidation protocol (vide supra), the compound with a sodium-cationized ion at $\mathrm{m} / \mathrm{z}$ 677 may result from the cleavage of the Sug $f$ $(1 \rightarrow 6)$-Gal $p$ (Sug $=$ Gal or periodate-oxidized $\mathrm{Gal})$ glycosidic linkage during periodate oxidation ( $\mathrm{pH} \sim 4.0)$ and the subsequent addition of a methyl group at O-6 of the Galp residue, whereas the compound having a $[\mathrm{M}+\mathrm{Na}]^{+}$ion at $m / z 680$ may be formed by cleavage of the Ara $f$ residue during the mild acid hydrolysis step and the subsequent addition of a deuterated methyl group.

The tandem mass spectrum obtained from the $[\mathrm{M}+\mathrm{Na}]^{+}$ion at $m / z 503$ showed a sodium-cationized fragment $\mathbf{B}_{\mathbf{1}}$ at $\mathrm{m} / z 244, \mathbf{C}_{\mathbf{1}}$ at $m / z 262$, and $\mathbf{Y}_{1}$ at $m / z 282$, corresponding to an O-permethylated alditol $\left(\mathrm{Hex}_{2}\right)-1-d$ containing three deuterated methyl groups. Fur- 
thermore, the tandem mass spectrum obtained from the $[\mathrm{M}+\mathrm{Na}]^{+}$ion at $m / z 506$ showed a sodium-cationized $\mathbf{B}_{1}$ fragment at $m / z 244$, a sodium-cationized $\mathbf{C}_{\mathbf{1}}$ fragment at $m / z$ 262, and an $\mathbf{Y}_{1}$ ion at $m / z 285$ indicating an O-permethylated alditol $\left(\mathrm{Hex}_{2}\right)-1-d$ containing four deuterated methyl groups. The disaccharide fragments with $[\mathrm{M}+\mathrm{Na}]^{+}$ions at $m / z 503$ and $m / z \quad 506$ originate from the tetrameric product with additional cleavage of the 6linked residue during the periodate oxidation or during the succeeding mild acid hydrolysis step, respectively, and with cleavage of the Rha residue at the reducing end during the mild acid hydrolysis step.

2D NMR spectroscopy. - Assignments of the ${ }^{1} \mathrm{H}$ chemical shifts of $\mathrm{n}$-EPS and dAc-EPS (Table 2) were performed by means of 2D TOCSY (mixing times 20, 75, and $150 \mathrm{~ms}$ ) and 2D NOESY experiments. Starting points for the interpretation of the spectra were the H-1 signals of residues $\mathbf{A}-\mathbf{F}$ and the methyl signals of residues $\mathbf{C}$ and $\mathbf{F}$. Comparison of TOCSY spectra with increasing mixing times allowed the assignment of the sequential order of the chemical shifts belonging to a single spin system.

In the TOCSY spectra of dAc-EPS, the A $\mathrm{H}-2,3,4$ resonances could be assigned on the TOCSY A H-1 track ( $\delta$ 4.696). The observation of an intraresidual connectivity A H-1,H3 in the NOESY spectrum (vide infra) at 3.78 ppm confirmed the overlap of the $\mathbf{A} \mathbf{H}-2$ and A $\mathrm{H}-3$ resonances. The intraresidual $\mathbf{A} \mathrm{H}-1, \mathrm{H}-$ 5 contact in the NOESY spectrum allowed the assignment of $\mathbf{A ~ H - 5}$. The resonances of $\mathbf{A}$ $\mathrm{H}-6 \mathrm{a}, 6 \mathrm{~b}$ were assigned via their correlation to the corresponding ${ }^{13} \mathrm{C}$ resonance in the ${ }^{13} \mathrm{C}-$ ${ }^{1} \mathrm{H}$ HSQC spectrum (vide infra). The TOCSY B H-1 track $(\delta$ 5.031) contains the complete series of cross-peaks with B H-2,3,4,5,6a,6b. On the TOCSY D H-1 track ( $\delta 5.16)$, crosspeaks with D H-2,3,4 were observed. The D $\mathrm{H}-5$ resonance was assigned through a crosspeak with D H-4 on the TOCSY D H-5 track $(\delta$ 4.382) and was confirmed in the NOESY spectrum (vide infra). The D H-6a,6b resonances were assigned through cross-peaks on the TOCSY D H-5 track $(\delta$ 4.382). All resonances of residue $\mathbf{E}(\mathrm{H}-2,3,4,5,6 \mathrm{a}, 6 \mathrm{~b})$ could be assigned on the TOCSY E H-1 track ( $\delta 5.17)$.
Beside it, the $\mathbf{E}(\mathrm{H}-5,6 \mathrm{a}, 6 \mathrm{~b})$ signals are clearly visible on the TOCSY $\mathbf{E}$ H-5 track $(\delta 4.24)$. The $\mathrm{H}-1,2,3,4,5$ resonances of residues $\mathbf{C}$ and F could be assigned via their TOCSY C-6 track (C H-6 $\delta$ 1.31, F H-6 $\delta$ 1.33).

The assigned ${ }^{1} \mathrm{H}$ chemical shifts, in combination with the monosaccharide and methylation analysis data demonstrated $\mathbf{C}$ and $\mathbf{F}$ to be the Rhap residues; their H-6 signals are characteristic for 6-deoxy-hexose. Furthermore, the characteristic downfield chemical shifts of the $\mathrm{H}-4$ signals of $\mathbf{A}, \mathbf{D}$, and $\mathbf{E}$ indicated these residues to represent $\mathrm{Gal} p$, leaving residue $\mathbf{B}$ to be the Galf residue.

Assignments of the ${ }^{1} \mathrm{H}$ chemical shifts of n-EPS (Table 2) were performed in essentially the same way as described for dAc-EPS. In addition, the $\mathbf{B}^{\prime} \mathrm{H}-1,3,4,5,6 \mathrm{a}, 6 \mathrm{~b}$ resonances of n-EPS could be assigned from the TOCSY $\mathbf{B}^{\prime}$ $\mathrm{H}-2$ track $(\delta$ 4.958). The differences in chemical shifts between $\mathbf{B}$ and $\mathbf{B}^{\prime} \mathrm{H}-1(\Delta \delta+0.12)$, $\mathbf{B}$ and $\mathbf{B}^{\prime} \mathrm{H}-2(\Delta \delta+0.87)$, and $\mathbf{B}$ and $\mathbf{B}^{\prime} \mathrm{H}-3$ $(\Delta \delta+0.16)$, and the similarity of the chemical shifts of $\mathbf{B}$ and $\mathbf{B}^{\prime} \mathrm{H}-4,5,6 \mathrm{a}, 6 \mathrm{~b}$ (within $\Delta \delta 0.06$ ) demonstrate that n-EPS is acetylated at O-2 of residue $\mathbf{B}$.

The 2D ${ }^{13} \mathrm{C}-{ }^{1} \mathrm{H}$ HSQC spectra of both dAc-EPS (Fig. 3) and n-EPS (data not shown) allowed the assignment of the ${ }^{13} \mathrm{C}$ chemical shifts and coupling constants (Table 2). It should be noted that the intense signal at $\delta$ 61.4 reflects two C-atoms, namely E C-6 (deduced via $\mathbf{E} \mathrm{H}-6 \mathrm{a}, 6 \mathrm{~b})$ and $\mathbf{A} \mathrm{C}-6$. Using the position of $\mathbf{A} \mathbf{C}-6$, the proton signals of $\mathbf{A}$ $\mathrm{H}-6 \mathrm{a}, \mathrm{b}$, which could not be allocated in the TOCSY and NOESY spectra, were assigned. By comparing the carbon chemical shifts of the polysaccharide with literature data of methyl aldosides ${ }^{21}$ the linkage pattern of the individual residues was determined. In case of dAc-EPS, residue $\mathbf{A}$ could be assigned as the 3 -substituted $\beta$-Gal $p$ unit, since A C-3 $(\delta$ 78.5) has shifted downfield in comparison to $\beta$-D$\mathrm{Gal} p 1 \mathrm{Me}\left(\delta_{\mathrm{C}-3}\right.$ 73.8). The upfield shift of $\mathbf{A}$ C-4 $(\delta$ 66.1) in comparison to $\beta-\mathrm{D}-\mathrm{Gal} p 1 \mathrm{Me}$ $\left(\delta_{\mathrm{C}-4} 69.7\right)$ has been reported before for a 3 -substituted $\beta$-D-Gal $p$ glycoside. ${ }^{22}$ Comparison of the ${ }^{13} \mathrm{C}$ chemical shifts of residue $\mathbf{B}$ with chemical shifts of $\alpha-\mathrm{D}-\mathrm{Gal} f 1 \mathrm{Me}\left(\delta_{\mathrm{C}-1}\right.$ $103.8, \delta_{\mathrm{C}-2} 78.2, \delta_{\mathrm{C}-3} 76.2, \delta_{\mathrm{C}-4} 83.1, \delta_{\mathrm{C}-5} 74.5$, $\left.\delta_{\mathrm{C}-6} 64.1\right)$ and $\beta-\mathrm{D}-\mathrm{Gal} f 1 \mathrm{Me}\left(\delta_{\mathrm{C}-1} 109.9, \delta_{\mathrm{C}-2}\right.$ 
Table 2

${ }^{1} \mathrm{H}$ NMR ${ }^{\mathrm{a}, \mathrm{b}}$ and ${ }^{13} \mathrm{C} \mathrm{NMR}{ }^{\mathrm{c}}$ chemical shifts of $\mathrm{S} 3$ native EPS (n-EPS) and O-deacetylated EPS (dAc-EPS), recorded in $\mathrm{D}_{2} \mathrm{O}$ at $80{ }^{\circ} \mathrm{C}$ for ${ }^{1} \mathrm{H}$ and at $67{ }^{\circ} \mathrm{C}$ for ${ }^{13} \mathrm{C}^{\mathrm{d}}$

\begin{tabular}{|c|c|c|c|c|c|c|}
\hline Residue & Proton & n-EPS & dAc-EPS & Carbon & n-EPS & dAc-EPS \\
\hline $\mathbf{A}$ & $\begin{array}{l}\mathrm{H}-1 \\
\mathrm{H}-2 \\
\mathrm{H}-3 \\
\mathrm{H}-4 \\
\mathrm{H}-5 \\
\mathrm{H}-6 \mathrm{a} \\
\mathrm{H}-6 \mathrm{~b}\end{array}$ & $\begin{array}{l}4.699 \\
3.79 \\
3.79 \\
4.13 \\
3.69 \\
3.7-3.8^{\mathrm{e}} \\
3.7-3.8^{\mathrm{e}}\end{array}$ & $\begin{array}{l}4.696 \\
3.77 \\
3.78 \\
4.11 \\
3.68 \\
3.7-3.8^{\mathrm{e}} \\
3.7-3.8^{\mathrm{e}}\end{array}$ & $\begin{array}{l}\text { C-1 } \\
\text { C-2 } \\
\text { C-3 } \\
\text { C-4 } \\
\text { C-5 } \\
\text { C-6 }\end{array}$ & $\begin{array}{r}104.8(164) \\
70.2 \\
78.3 \\
66.1 \\
75.3 \\
61.4\end{array}$ & $\begin{array}{c}104.8(163) \\
70.3 \\
78.5 \\
66.1 \\
75.4 \\
61.4\end{array}$ \\
\hline B & $\begin{array}{l}\text { H-1 } \\
\text { H-2 } \\
\text { H-3 } \\
\text { H-4 } \\
\text { H-5 } \\
\text { H-6a } \\
\text { H-6b }\end{array}$ & $\begin{array}{l}5.03 \\
4.09 \\
4.06 \\
3.99 \\
3.84 \\
3.73 \\
3.66\end{array}$ & $\begin{array}{l}5.031 \\
4.09 \\
4.06 \\
3.98 \\
3.84 \\
3.71 \\
3.66\end{array}$ & $\begin{array}{l}\text { C-1 } \\
\text { C-2 } \\
\text { C-3 } \\
\text { C-4 } \\
\text { C-5 } \\
\text { C-6 }\end{array}$ & $\begin{array}{r}108.1(177) \\
78.4 \\
77.5 \\
84.0 \\
71.5 \\
63.3\end{array}$ & $\begin{array}{r}108.1(177) \\
78.5 \\
77.5 \\
84.0 \\
71.6 \\
63.4\end{array}$ \\
\hline $\mathrm{C}$ & $\begin{array}{l}\mathrm{H}-1 \\
\mathrm{H}-2 \\
\mathrm{H}-3 \\
\mathrm{H}-4 \\
\mathrm{H}-5 \\
\mathrm{H}-6\end{array}$ & $\begin{array}{l}5.05 \\
4.26 \\
3.86 \\
3.590 \\
3.78 \\
1.31\end{array}$ & $\begin{array}{l}5.051 \\
4.26 \\
3.85 \\
3.590 \\
3.77 \\
1.31\end{array}$ & $\begin{array}{l}\text { C-1 } \\
\text { C-2 } \\
\text { C-3 } \\
\text { C-4 } \\
\text { C-5 } \\
\text { C-6 }\end{array}$ & $\begin{array}{r}102.3(174) \\
67.7 \\
77.3 \\
71.2 \\
69.7 \\
17.0\end{array}$ & $\begin{array}{c}102.4(174) \\
67.7 \\
77.2 \\
71.2 \\
69.6 \\
17.1\end{array}$ \\
\hline $\mathbf{E}$ & $\begin{array}{l}\mathrm{H}-1 \\
\mathrm{H}-2 \\
\mathrm{H}-3 \\
\mathrm{H}-4 \\
\mathrm{H}-5 \\
\mathrm{H}-6 \mathrm{a} \\
\mathrm{H}-6 \mathrm{~b}\end{array}$ & $\begin{array}{l}5.17 \\
3.99 \\
4.10 \\
4.06 \\
4.24 \\
3.76 \\
3.76\end{array}$ & $\begin{array}{l}5.17 \\
3.98 \\
4.11 \\
4.06 \\
4.24 \\
3.76 \\
3.76\end{array}$ & $\begin{array}{l}\text { C-1 } \\
\text { C-2 } \\
\text { C-3 } \\
\text { C-4 } \\
\text { C-5 } \\
\text { C-6 }\end{array}$ & $\begin{array}{l}96.0(176) \\
74.5 \\
69.8 \\
70.2 \\
71.5 \\
61.4\end{array}$ & $\begin{array}{l}96.0(176) \\
74.6 \\
69.8 \\
70.3 \\
71.6 \\
61.4\end{array}$ \\
\hline $\mathbf{F}$ & $\begin{array}{l}\mathrm{H}-1 \\
\mathrm{H}-2 \\
\mathrm{H}-3 \\
\mathrm{H}-4 \\
\mathrm{H}-5 \\
\mathrm{H}-6\end{array}$ & $\begin{array}{l}5.245 \\
4.10 \\
3.90 \\
3.506 \\
3.72 \\
1.33\end{array}$ & $\begin{array}{l}5.246 \\
4.09 \\
3.89 \\
3.507 \\
3.71 \\
1.33\end{array}$ & $\begin{array}{l}\text { C-1 } \\
\text { C-2 } \\
\text { C-3 } \\
\text { C-4 } \\
\text { C-5 } \\
\text { C-6 }\end{array}$ & $\begin{array}{l}100.9(177) \\
81.6 \\
\text { nd } \\
\text { nd } \\
\text { nd } \\
17.0\end{array}$ & $\begin{array}{r}100.9(177) \\
81.7 \\
70.8 \\
72.9 \\
69.8 \\
17.1\end{array}$ \\
\hline
\end{tabular}

${ }^{a}$ In ppm relative to the signal of internal acetone at $\delta 2.225$.

${ }^{\mathrm{b}}$ Accurate ${ }^{1} \mathrm{H}$ chemical shift values obtained from 1D spectra are represented with three decimals, whereas ${ }^{1} \mathrm{H}$ chemical shift values obtained from $2 \mathrm{D}$ spectra are depicted with two decimals.

${ }^{\mathrm{c}}$ In ppm relative to the $\alpha$ anomeric signal of external $\left[1-{ }^{13} \mathrm{C}\right] \mathrm{glucose}$ at $\delta$ 92.9.

${ }^{\mathrm{d}}{ }^{1} J_{\mathrm{C}-1, \mathrm{H}-1}$ values $(\mathrm{Hz})$ are included in parentheses.

e Assigned from ${ }^{13} \mathrm{C}-{ }^{1} \mathrm{H}$ HSQC spectra. 
$\left.81.3, \delta_{\mathrm{C}-3} 78.4, \delta_{\mathrm{C}-4} 84.7, \delta_{\mathrm{C}-5} 71.7, \delta_{\mathrm{C}-6} 63.6\right)^{21}$ showed this residue to be terminal $\beta$-Galf. The downfield chemical shift of $\mathbf{E}$ C-2 $\left(\begin{array}{l}\delta \\ \end{array}\right.$ 74.6) demonstrated residue $\mathbf{E}$ to represent the 2-substituted $\alpha-\mathrm{Gal} p$ residue $\left(\alpha-\mathrm{D}-\mathrm{Gal} p 1 \mathrm{Me}, \delta_{\mathrm{C}-2}\right.$ 69.2). The downfield chemical shifts for C-3 $(\delta$ 77.2) of residue $\mathbf{C}$ and $\mathrm{C}-2(\delta 81.7)$ of residue $\mathbf{F}$ indicate that these $\alpha$-Rha $p$ units are 3- and 2-substituted, respectively $\left(\alpha\right.$-L-Rhap $1 \mathrm{Me}, \delta_{\mathrm{C}-2}$ $\left.71.0, \delta_{\mathrm{C}-3} 71.3\right)$. Finally, residue $\mathbf{D}$ could be assigned as the 3,6-substituted $\alpha-\mathrm{Gal} p$ unit, since the D C-3 and D C-6 signals $\left(\delta_{\mathrm{C}-3} 79.6\right.$, $\left.\delta_{\mathrm{C}-6} 67.0\right)$ are shifted downfield in comparison to their methyl aldosides $\left(\alpha-\mathrm{D}-\mathrm{Gal} p 1 \mathrm{Me}, \mathrm{C}_{\mathrm{C}-3}\right.$ $\delta 70.5, \mathrm{C}_{\mathrm{C}-6} \delta 62.2$ ).

The sequence of the monosaccharides in the polysaccharide repeating unit was determined by means of a NOESY experiment (Fig. 4). On the NOESY $\mathbf{C ~ H - 1 ~ t r a c k ~ o f ~ d A c - E P S ~ a n ~}$ interresidual connectivity with $\mathbf{F ~} \mathrm{H}-2$ was in accordance with the $\mathbf{C}(1 \rightarrow 2) \mathbf{F}$ sequence. A well-resolved NOE between $\mathbf{F} \mathrm{H}-1$ and $\mathbf{E ~ H - 2}$
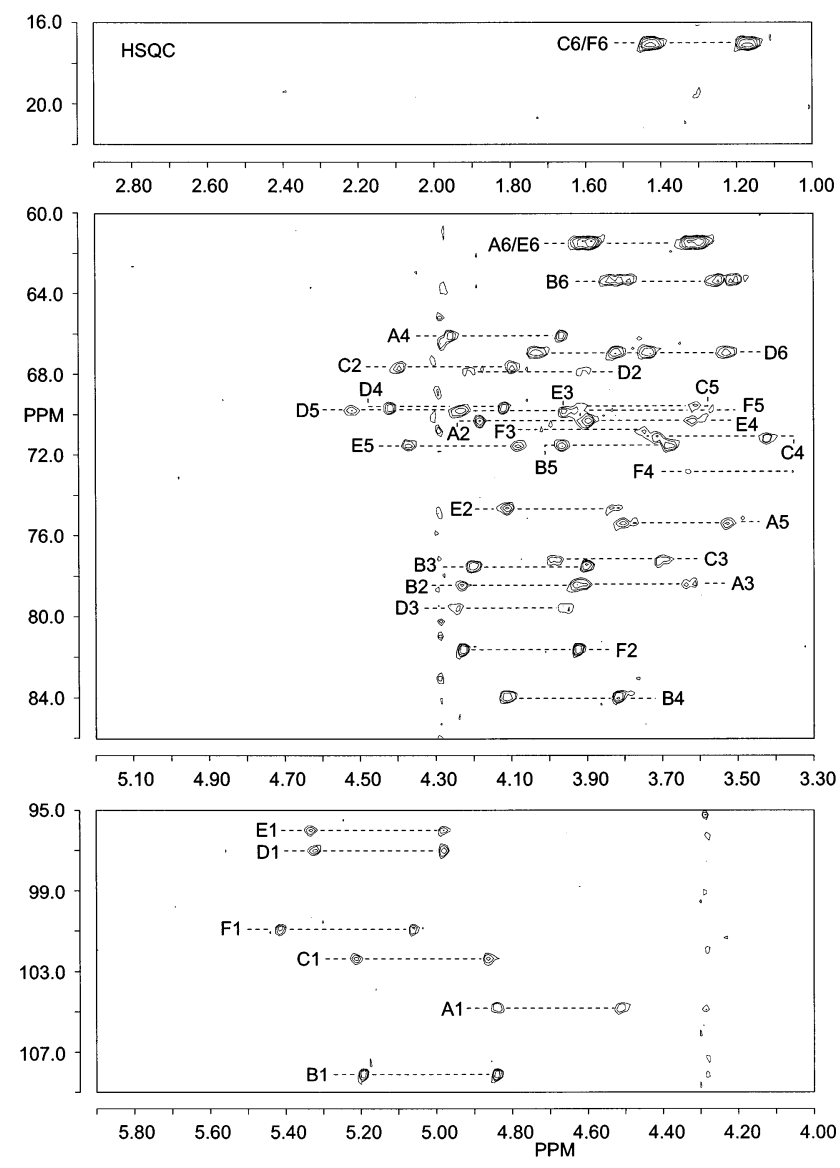

Fig. 3. 500-MHz $2 \mathrm{D}{ }^{13} \mathrm{C}-{ }^{1} \mathrm{H}$ undecoupled HSQC spectrum of dAc-EPS, recorded in $\mathrm{D}_{2} \mathrm{O}$ at $67^{\circ} \mathrm{C}$. A1 stands for the set of cross-peaks between $\mathrm{H}-1$ and $\mathrm{C}-1$ of residue $\mathbf{A}$, etc.

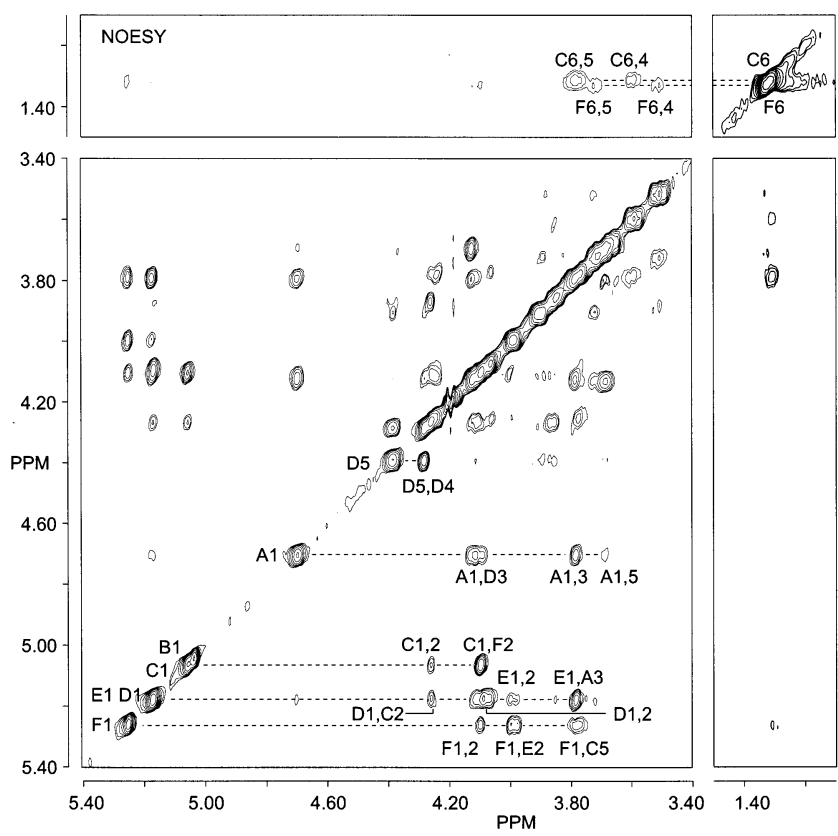

Fig. 4. 500-MHz 2D NOESY spectrum (mixing time $200 \mathrm{~ms}$ ) of dAc-EPS, recorded in $\mathrm{D}_{2} \mathrm{O}$ at $80^{\circ} \mathrm{C}$. $\mathrm{F} 1$ corresponds to the diagonal peak belonging to residue $\mathbf{F} \mathrm{H}-1 ; \mathrm{F} 1,2$ refers to an intraresidual cross-peak between $\mathbf{F} \mathrm{H}-1$ and $\mathbf{F}$ H-2, and F1, E2 means an interresidual connectivity between $\mathbf{F} \mathrm{H}-1$ and $\mathbf{E}$ $\mathrm{H}-2$, etc.

was observed, revealing a $\mathbf{F}(1 \rightarrow 2) \mathbf{E}$ linkage. The NOE between $\mathbf{F} \mathrm{H}-1$ and $\mathbf{C}$ H-5 reflects the closeness in space of these protons in the $\mathbf{C}(1 \rightarrow 2) \mathbf{F}(1 \rightarrow 2) \mathbf{E}$ sequence. The interresidual connectivity between $\mathbf{E ~ H - 1}$ and A H-2,3 indicated an $\mathbf{E}(1 \rightarrow 3) \mathbf{A}$ linkage since carbon chemical shifts revealed residue A to be substituted at O-3. The NOE between $\mathbf{A}$ H-1 and D H-3 demonstrated an $\mathbf{A}(1 \rightarrow 3) \mathbf{D}$ linkage. Furthermore, an NOE between $\mathbf{D} \mathrm{H}-1$ and $\mathbf{C} \mathrm{H}-2$ was observed. This NOE represents a $\mathbf{D}(1 \rightarrow 3) \mathbf{C}$ linkage, since methylation analysis in combination with carbon chemical shifts demonstrated residue $\mathbf{C}$ to be 3 -substituted. The observation of such non-glycosidic NOE cross-peaks has been reported previously for the $\alpha$-D-Gal $p-(1 \rightarrow 3)-\alpha-\mathrm{L}-\mathrm{Rh}$ h $p$ linkage in the EPS of S. thermophilus Rs and Sts. ${ }^{18}$ The $\mathbf{B}(1 \rightarrow 6) \mathbf{D}$ linkage determined by partial acid hydrolysis and methylation analysis, could not be confirmed by the NOESY experiment.

The intraresidual connectivities in the NOESY spectrum confirm the anomeric configurations of the various monosaccharide residues in the polysaccharide.

By combining the various analytical data described above, the structure of the repeating 
unit of the EPS produced by $S$. thermophilus $\mathrm{S} 3$ can be illustrated as:

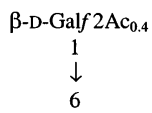

$\rightarrow 3)-\beta$-D-Galp-( $(1 \rightarrow 3)-\alpha-D-G a l p-(1 \rightarrow 3)-\alpha-L-R h a p-(1 \rightarrow 2)-\alpha$-L-Rhap-( $(1 \rightarrow 2)-\alpha$-D-Galp-( $(1 \rightarrow$

Concluding remarks. - In this paper, the complete elucidation of the structure of the EPS isolated from $S$. thermophilus $\mathrm{S} 3$ grown in skimmed milk is described. Several EPSs produced by strains of $S$. thermophilus have been isolated from yogurt, or related media, and their structures studied. ${ }^{15-18}$ A number of the EPSs are structurally related polysaccharides and include the EPSs produced by $S$. thermophilus Sfi12, ${ }^{17}$ OR 901, ${ }^{16} \mathrm{Rs},{ }^{18} \mathrm{Sts},{ }^{18}$ and S3, of which the OR 901, Rs and Sts EPSs have identical repeating units. The EPSs are characterized by the presence of a pentameric backbone containing a $\rightarrow 3)-\alpha-\mathrm{D}-\mathrm{Gal} p-(1 \rightarrow 3)$ $\alpha$-L-Rha $p-(1 \rightarrow 2)-\alpha-$-Rha $p-(1 \rightarrow 2)-\alpha-D-G a l p$ $(1 \rightarrow 3)$-Hexp-( $1 \rightarrow$ sequence, wherein the fifth residue differs by the presence of $\alpha-\mathrm{D}-\mathrm{Glc} p$ for Sfi12, $\alpha-\mathrm{D}-\mathrm{Gal} p$ for OR 901, Rs and Sts, and $\beta-\mathrm{D}-\mathrm{Gal} p$ for the EPS produced by S3. Furthermore, the EPSs differ in the attachment site of the side chain, as well as in the composition of the side chain.

Although the EPSs produced by several $S$. thermophilus strains share structural features, strains producing EPS with only minor differences in the primary structure of the repeating unit (e.g. single monosaccharide replacement, molecular size) are excellent probes to obtain insight into the relationship between physical properties, such as ropiness, and the structure of the EPS. In this regard, research performed towards biosynthetic engineering techniques as well as genetic engineering techniques to tailor EPSs produced by lactic acid bacteria may assist in creating structural diversity in polysaccharides allowing the establishment of the structure-function relationship of EPS produced by lactic acid bacteria.

\section{Experimental}

Organism and culture conditions. $-S$. thermophilus S3 is a highly ropy strain obtained from NIZO food research (Ede, The Netherlands). The cultivation of $S$. thermophilus S3 was performed in pasteurized reconstituted skimmed milk as described. ${ }^{18}$

Exopolysaccharide concentration. - The concentration of exopolysaccharide was determined by HP-GPC with RI-detection as previously described. ${ }^{18}$

Isolation and purification of the exopolysaccharide.-To the milk culture, trichloroacetic acid was added to a final concentration of $4 \%$ $(\mathrm{w} / \mathrm{w})$. After stirring for $1 \mathrm{~h}$, cells and precipitated proteins were removed by centrifugation $\left(2 \times 30 \mathrm{~min}\right.$ at $\left.16,300 g, 4^{\circ} \mathrm{C}\right)$. EPS was precipitated from the supernatant by addition of 2 vol of $\mathrm{EtOH}\left(4^{\circ} \mathrm{C}\right)$. An aq solution of the precipitated material was extensively dialyzed against running tap water and after the removal of insoluble material by centrifugation, 2 vol of EtOH were added. The precipitate formed was redissolved in water, and purified by a precipitation with $50 \%(\mathrm{v} / \mathrm{v})$ acetone.

Molecular mass determination. - The average molecular mass of n-EPS was determined by using a combination of gel-permeation chromatography, static light scattering, and differential refraction analysis, as described. ${ }^{23}$

Gas-liquid chromatography and mass spectrometry. - GLC analyses were performed on a Chrompack CP9002 gas chromatograph equipped with a CP-Sil 5CB fused silica capillary column $(25 \mathrm{~m} \times 0.32 \mathrm{~mm}$, Chrompack) or a CP-Sil 43CB fused silica capillary column (25 $\mathrm{m} \times 0.25 \mathrm{~mm}$, Chrompack). GLC-MS analyses were carried out on a MD800/8060 system (Fisons instruments; electron energy, $70 \mathrm{eV}$ ), using a CP-Sil 5CB fused silica capillary column $(25 \mathrm{~m} \times 0.25 \mathrm{~mm}$, Chrompack $)$. Both GLC and GLC-MS analyses were performed under conditions described previously. ${ }^{18}$ Positive-ion mode nanoES-CID tandem mass spectra were obtained on a Micromass Q-TOF hybrid tandem mass spectrometer equipped with a nanospray ion source (Bijvoet Center, Department of Biomolecular Mass Spectrometry) essentially according to Ref. 24. Argon was used as collision gas with collision energy of approximately $50 \mathrm{eV}$. Fragment ions were labeled according to the nomenclature of Domon and Costello. ${ }^{25}$

Monosaccharide and methylation analysis.For monosaccharide analysis, the dry polysac- 
charide was subjected to methanolysis, followed by trimethylsilylation and GLC analysis as described. ${ }^{26,27}$ The absolute configuration of the monosaccharides was determined according to Refs. 28 and 29. For methylation analysis, polysaccharides were permethylated using $\mathrm{CH}_{3} \mathrm{I}$ and solid $\mathrm{NaOH}$ in $\mathrm{Me}_{2} \mathrm{SO}$ as described previously. ${ }^{30}$ Subsequently, the methylated saccharides were hydrolyzed with $2 \mathrm{M}$ $\mathrm{CF}_{3} \mathrm{COOH}\left(2 \mathrm{~h}, 120^{\circ} \mathrm{C}\right)$ and reduced with $\mathrm{NaBD}_{4}$. After neutralization and removal of boric acid by coevaporation with $\mathrm{MeOH}$, the mixtures of partially methylated alditols were acetylated with $\mathrm{Ac}_{2} \mathrm{O}\left(3 \mathrm{~h}, 120^{\circ} \mathrm{C}\right)$, and analyzed by GLC and GLC-MS. ${ }^{26,31}$

Periodate oxidation. - To a solution of polysaccharide $(30 \mathrm{mg})$ in $0.1 \mathrm{M} \mathrm{NaOAc}$ buffer (30 mL, pH 3.9), $\mathrm{NaIO}_{4}$ was added to a final concentration of $50 \mathrm{mM}$, and the mixture was kept in the dark for 5 days at $4{ }^{\circ} \mathrm{C}$. Excess of periodate was destroyed by the addition of ethylene glycol $(2 \mathrm{~mL})$ after which the solution was dialyzed against tap water. The oxidized polysaccharide was reduced with $\mathrm{NaBH}_{4}(4 \mathrm{~h}$, $20^{\circ} \mathrm{C}$ ), and permethylated as described above. The obtained permethylated material was subsequently hydrolyzed $\left(0.5 \mathrm{M} \mathrm{CF}_{3} \mathrm{COOH}, 75\right.$ min, $\left.100^{\circ} \mathrm{C}\right)$, reduced with $\mathrm{NaBD}_{4}(4 \mathrm{~h}$, $20^{\circ} \mathrm{C}$ ), and permethylated using $\mathrm{CD}_{3} \mathrm{I}$.

$O$-Deacetylation of the polysaccharide.Native polysaccharide (30 mg) was O-deacetylated by treatment with aq $5 \% \mathrm{NH}_{4} \mathrm{OH}$ $(30 \mathrm{~mL})$ for $8 \mathrm{~h}$ at $\mathrm{rt}$. The O-deacetylated polysaccharide was recovered by lyophilization.

NMR spectroscopy.-Prior to NMR spectroscopic analysis, samples were exchanged twice in 99.9 atom $\% \mathrm{D}_{2} \mathrm{O}$ (Isotec) with intermediate lyophilization, and finally dissolved in 99.96 atom $\% \mathrm{D}_{2} \mathrm{O}$ (Isotec). The $\mathrm{pH}$ of the samples was adjusted to 7.0 using NaOD. 1D and 2D NMR spectra were recorded on a Bruker AMX-500 spectrometer (Bijvoet Center, Department of NMR Spectroscopy). The HOD signal was suppressed either by applying a WEFT pulse sequence ${ }^{32}$ in $1 \mathrm{D}^{1} \mathrm{H}$ NMR experiments, or by presaturation for $0.8-1 \mathrm{~s}$ in $2 \mathrm{D}$ experiments. Chemical shifts are expressed in ppm by reference to internal acetone $(\delta 2.225)$ for ${ }^{1} \mathrm{H}$ or to the $\alpha$ anomeric signal of external $\left[1-{ }^{13} \mathrm{C}\right]$ glucose $\left(\delta_{\mathrm{C}-1} 92.9\right)$ for
${ }^{13} \mathrm{C}$. Homonuclear NMR experiments were recorded at a probe temperature of $80^{\circ} \mathrm{C}$ and heteronuclear NMR experiments at a probe temperature of $67^{\circ} \mathrm{C}$, using a spectral width of 4032 and $16350 \mathrm{~Hz}$ for ${ }^{1} \mathrm{H}$ and ${ }^{13} \mathrm{C}$, respectively. Resolution enhancement of the spectra was performed by a Lorentzian-to-Gaussian transformation and when necessary, a fourthorder polynomial baseline correction was performed. 2D TOCSY spectra were recorded using a 'clean' MLEV-17 mixing sequence with an effective spin-lock time of 20-150 ms. 2D NOESY experiments were performed with a mixing time of $200 \mathrm{~ms}$, and the natural abundance ${ }^{13} \mathrm{C}-{ }^{1} \mathrm{H}$ 2D HSQC experiment was recorded without decoupling during acquisition of the ${ }^{1} \mathrm{H}$ FID. All NMR data were processed using TRITON (Bijvoet Center, Department of NMR Spectroscopy) or Bruker UXNMR software.

\section{Acknowledgements}

This study was supported by the PBTS Research Program with financial aid from the Ministry of Economic Affairs and by the Integral Structure Plan for the Northern Netherlands from the Dutch Development Company. The authors thank F. Kingma (NIZO Food Research, Ede, The Netherlands) for cultivation of $S$. thermophilus S3 and for HP-GPC analysis, R. Tuinier (NIZO Food Research, Ede, The Netherlands) for molecular mass analysis, and C. Versluis (Bijvoet Center, Department of Biomolecular Mass Spectrometry, Utrecht University, The Netherlands) for recording the ES-MS/MS spectra.

\section{References}

1. Sutherland, I. W. Trends Biotechnol. 1998, 16, 41-46.

2. Robijn, G. W.; Gutiérrez Gallego, R.; van den Berg, D. J. C.; Haas, H.; Kamerling, J. P.; Vliegenthart, J. F. G. Carbohydr. Res. 1996, 288, 203-218.

3. Gruter, M.; Leeflang, B. R.; Kuiper, J.; Kamerling, J. P.; Vliegenthart, J. F. G. Carbohydr. Res. 1993, 239, 209226.

4. Yamamoto, Y.; Murosaki, S.; Yamauchi, R.; Kato, K.; Sone, Y. Carbohydr. Res. 1994, 261, 67-78.

5. Yamamoto, Y.; Nunome, T.; Yamauchi, R.; Kato, K.; Sone, Y. Carbohydr. Res. 1995, 275, 319-332. 
6. Robijn, G. W.; Thomas, J. R.; Haas, H.; van den Berg, D. J. C.; Kamerling, J. P.; Vliegenthart, J. F. G. Carbohydr. Res. 1995, 276, 137-154.

7. Staaf, M.; Widmalm, G.; Yang, Z.; Huttunen, E. Carbohydr. Res. 1996, 291, 155-164.

8. Stingele, F.; Lemoine, J.; Neeser, J.-R. Carbohydr. Res. 1997, 302, 197-202.

9. Robijn, G. W.; Wienk, H. L. J.; van den Berg, D. J. C.; Haas, H.; Kamerling, J. P.; Vliegenthart, J. F. G. Carbohydr. Res. 1996, 285, 129-139.

10. van Geel-Schutten, G. H.; Faber, E. J.; Smit, E.; Bonting, K.; Smith, M. R.; ten Brink, B.; Kamerling, J. P.; Vliegenthart, J. F. G.; Dijkhuizen, L. Appl. Environ. Microbiol. 1999, 65, 3008-3014.

11. Vanhaverbeke, C.; Bosso, C.; Colin-Morel, P.; Gey, C.; Gamar-Nourani, L.; Blondeau, K.; Simonet, J.-M.; Heyraud, A. Carbohydr. Res. 1998, 314, 211-220.

12. Robijn, G. W.; van den Berg, D. J. C.; Haas, H.; Kamerling, J. P.; Vliegenthart, J. F. G. Carbohydr. Res. 1995, 276, 117-136.

13. Nakajima, H.; Hirota, T.; Toba, T.; Itoh, T.; Adachi, S. Carbohydr. Res. 1992, 224, 245-253.

14. Gruter, M.; Leeflang, B. R.; Kuiper, J.; Kamerling, J. P.; Vliegenthart, J. F. G. Carbohydr. Res. 1992, 231, 273291.

15. Doco, T.; Wieruszeski, J.-M.; Fournet, B.; Carcano, D.; Ramos, P.; Loones, A. Carbohydr. Res. 1990, 198, 313321.

16. Bubb, W. A.; Urashima, T.; Fujiwara, R.; Shinnai, T.; Ariga, H. Carbohydr. Res. 1997, 301, 41-50.

17. Lemoine, J.; Chirat, F.; Wieruszeski, J.-M.; Strecker, G.; Favre, N.; Neeser, J.-R. Appl. Environ. Microbiol. 1997, 63, 3512-3518.
18. Faber, E. J.; Zoon, P.; Kamerling, J. P.; Vliegenthart, J. F. G. Carbohydr. Res. 1998, 310, 269-276.

19. Aspinall, G. O. In The Polysaccharides; Aspinall, G. O., Ed.; Academic: New York, 1982; Vol. 1, pp. 81-86.

20. Brüll, L. P.; Kovácik, V.; Thomas-Oates, J. E.; Heerma, W.; Haverkamp, J. Rapid Commun. Mass Spectrom. 1998, 12, 1520-1532.

21. Bock, K.; Pedersen, C. Adv. Carbohydr. Chem. Biochem. 1983, 41, 27-66.

22. Kol, O.; Wieruszeski, J.-M.; Strecker, G.; Fournet, B.; Zalisz, R.; Smets, P. Carbohydr. Res. 1992, 236, 339-344.

23. Tinland, B.; Mazet, J.; Rinaudo, M. Makromol. Chem. 1988, 9, 69-73.

24. Samuelsen, A. B.; Cohen, E. H.; Paulsen, B. S.; Brüll, L. P.; Thomas-Oates, J. E. Carbohydr. Res. 1999, 315, 312318.

25. Domon, B.; Costello, C. E. Glycoconjugate J. 1988, 5, 397-409.

26. Chaplin, M. F. Anal. Biochem. 1982, 123, 336-341.

27. Kamerling, J. P.; Vliegenthart, J. F. G. In Mass Spectrometry; Lawson, A. M., Ed. Clinical biochemistry principles, methods, applications. Walter de Gruyter: Berlin, 1989; Vol. 1, pp. 176-263.

28. Gerwig, G. J.; Kamerling, J. P.; Vliegenthart, J. F. G. Carbohydr. Res. 1978, 62, 349-357.

29. Gerwig, G. J.; Kamerling, J. P.; Vliegenthart, J. F. G. Carbohydr. Res. 1979, 77, 1-7.

30. Ciucanu, I.; Kerek, F. Carbohydr. Res. 1984, 131, 209217.

31. Jansson, P.-E.; Kenne, L.; Liedgren, H.; Lindberg, B.; Lönngren, J. Chem. Commun. Univ. Stockholm 1976, 8, $1-74$.

32. Hård, K.; van Zadelhoff, G.; Moonen, P.; Kamerling, J. P.; Vliegenthart, J. F. G. Eur. J. Biochem. 1992, 209, 895-915. 